\title{
CAPÍTULO 12: MONITORAMENTO TECNOLÓGICO DE PATENTES ENVOLVENDO PREBIÓTICOS NO CENÁRIO GLOBAL E BRASILEIRO
}

\author{
CAPÍTULO 12: SEGUIMIENTO DE PATENTES TECNOLÓGICAS CON \\ PREBIÓTICOS EN EL ESCENARIO GLOBAL Y BRASILEÑO
}

\section{CHAPTER 12: TECHNOLOGICAL PATENT MONITORING INVOLVING PREBIOTICS IN THE GLOBAL AND BRAZILIAN SCENARIO}

\author{
Wanessa Braz da Silva ${ }^{1}$; Maria Eduarda Menezes Rocha ${ }^{2}$; Nathan Gabriel Barbosa Moura ${ }^{3}$; Rodrigo Lira de \\ Oliveira ${ }^{4}$ Tatiana Souza Porto ${ }^{5}$
}

DOI: $\underline{\text { https://doi.org/10.31692/978-65-88970-19-5.178-197 }}$

\begin{abstract}
RESUMO
Diante da crescente preocupação com uma vida mais saudável, tem-se observado uma maior procura por alimentos que apresentem efeitos positivos na saúde. Dentre os alimentos funcionais, os prebióticos se destacam como componentes não digeríveis que afetam beneficamente o hospedeiro pelo estímulo seletivo da proliferação ou atividade de populações de bactérias desejáveis no cólon. Este trabalho objetivou-se em realizar uma prospecção tecnológica sobre o desenvolvimento e aplicação nacional e internacional de patentes sobre prebióticos tendo como base para essa análise as plataformas Derwent, Espacenet, Lens, INPI, Patentscope e USPTO. A plataforma Lens obteve o maior número de patentes (5241 documentos) e por isto foi a base de dados selecionada para a realização do monitoramento tecnológico sobre prebióticos. Em relação aos registros, 75\% correspondiam à pedidos de patente e $15 \%$ as patentes que foram concedidas. O país que lidera o número de depósitos é a China com aproximadamente $38 \%$ do total. No que diz respeito as organizações requerentes, a Nestec $S A$ foi a organização que mais realizou depósitos de patentes, um total de 175 registros. Também foram analisados os dados de Classificação Internacional de Patentes (IPC), no qual $30 \%$ se referem a seção A23L que compreendem alimentos, produtos alimentícios ou bebidas não alcoólicas, indicando ser uma excelente aplicação para a indústria de alimentos. No Brasil, a base de dados nacional INPI apresentou 122 pedidos de patentes sobre prebióticos, onde o Brasil é o principal depositante com $48 \%$ do total. Com relação ao depositante, $54 \%$ dos pedidos de patente são de empresas privadas, seguidos por $37 \%$ de instituições públicas e $9 \%$ por pessoas físicas. No geral, os resultados mostram que os avanços nas pesquisas sobre prebióticos são promissores e esse estudo pode contribuir no planejamento e tomada de decisões para o desenvolvimento dessa área.
\end{abstract}

Palavras-Chave: Prebióticos, Prospeção tecnológica, Patentes, Panorama global.

\section{RESUMEN}

\footnotetext{
${ }^{1}$ Engenharia de Alimentos, Universidade Federal do Agreste de Pernambuco, wanessa.braz09@gmail.com

${ }^{2}$ Engenharia de Alimentos, Universidade Federal do Agreste de Pernambuco, eduardamenezes32@gmail.com

${ }^{3}$ Engenharia de Alimentos, Universidade Federal do Agreste de Pernambuco, nathangabriel1515@gmail.com

${ }^{4}$ Bolsista de pós-doutorado, Universidade Federal do Agreste de Pernambuco, rodrigolira1@outlook.com

${ }^{5}$ Doutora em tecnologia Bioquímico-Farmacêutica, Universidade Federal do Agreste de Pernambuco, portots@yahoo.com
} 
Ante la creciente preocupación por una vida más sana, ha habido una mayor demanda de alimentos que tienen efectos positivos en la salud. Entre los alimentos emitidos, los prebióticos se destacan como componentes no digeribles que afectan beneficiosamente al huésped al estimular activamente la proliferación o actividad de poblaciones bacterianas deseables en el colon. Este trabajo tuvo como objetivo realizar un relevamiento tecnológico sobre el desarrollo y aplicación nacional e internacional de patentes de prebióticos a partir de este análisis como plataformas Derwent, Espacenet, Lens, INPI, Patentscope y USPTO. La plataforma Lens obtuvo el mayor número de patentes (5241 documentos) y por ello fue la base de datos facilitada para realizar el seguimiento de prebióticos. En cuanto a los registros, el $75 \%$ corresponde a solicitudes de patentes y el $15 \%$ a patentes otorgadas. El país que lidera el número de depósitos es China con aproximadamente el $38 \%$ del total. En cuanto a las asociaciones solicitantes, Nestec $S A$ fue la organización que presentó más solicitudes de patente, un total de 175 registros. También se disiparon los datos de la Clasificación Internacional de Patentes (IPC), no del cual el $30 \%$ se refirió a la sección A23L que comprende alimentos, productos alimenticios o bebidas no alcohólicas, lo que indica que es una excelente aplicación para la industria alimentaria. En Brasil, una base de datos nacional del INPI presentó 122 solicitudes de patente sobre prebióticos, donde Brasil es el principal depositante con el $48 \%$ del total. En cuanto al depositante, el $54 \%$ de las solicitudes de patentes son de empresas privadas, seguido del $37 \%$ de instituciones públicas y el $9 \%$ de particulares. En general, los resultados muestran que los avances en la investigación sobre prebióticos son prometedores y este estudio puede contribuir a la planificación y toma de decisiones para el desarrollo de esta área.

Palabras Clave: Prebióticos, Prospección tecnológica, Patentes, Perspectiva global.

\section{ABSTRACT}

In view of the growing concern with a healthier life, there has been a greater demand for foods that have positive effects on health. Among the foods emitted, prebiotics stand out as non-digestible components that beneficially affect the host by actively stimulating the proliferation or activity of desirable bacterial populations in the colon. This work aimed to carry out a technological research on the development and national and international application of patents on prebiotics based on this analysis as Derwent, Espacenet, Lens, INPI, Patentscope and USPTO platforms. The Lens platform obtained the highest number of patents (5241 documents) and for this reason it was the database provided for monitoring prebiotics. Regarding registrations, $75 \%$ correspond to patent applications and $15 \%$ to patents that have been granted. The country that leads the number of deposits is China with approximately $38 \%$ of the total. With regard to the applicant associations, Nestec SA was the organization that filed more patent applications, a total of 175 registrations. The International Patent Classification (IPC) data was also dissipated, not which $30 \%$ referred to section A23L which comprise food, food products or non-alcoholic beverages, indicating that it is an excellent application for the food industry. In Brazil, a national INPI database submitted 122 patent applications on prebiotics, where Brazil is the main depositor with $48 \%$ of the total. Regarding the depositor, $54 \%$ of patent applications are from private companies, followed by $37 \%$ from public institutions and $9 \%$ from individuals. Overall, the results show that advances in research on prebiotics are promising and this study can contribute to planning and decision-making for the development of this area.

Keywords: Prebiotics, Technological prospecting, Patents, Global landscape.

\section{INTRODUÇÃO}

A crescente preocupação com a saúde e o bem-estar têm proporcionado um aumento na procura por alimentos funcionais. Estes, apresentam um efeito positivo na saúde, além de suas funções nutricionais básicas (NITHYABALASUNDARI et al., 2020). Os alimentos 
funcionais compreendem: (i) alimentos tradicionais com substâncias bioativas de ocorrência natural como a fibra alimentar, (ii) alimentos suplementados com substâncias bioativas como probióticos e antioxidantes e (iii) ingredientes alimentares introduzidos em alimentos convencionais como os prebióticos (AL-SHERAJIA et al.,2013). A legislação brasileira não determina o que são alimentos funcionais, mas a Resolução no 19, de 30 de abril de 1999 apresenta uma definição para alegação de propriedade funcional que "é aquela relativa ao papel metabólico ou fisiológico que o nutriente ou não nutriente tem no crescimento, desenvolvimento, manutenção e outras funções normas do organismo humano" (BRASIL, 1999).

Dentre esses alimentos, se destacam os prebióticos que são substratos que estimulam o crescimento e/ou ativam o metabolismo de algum grupo de bactérias benéficas (ROSA et al., 2021). Estimasse que o mercado global de prebióticos deve crescer cerca de 12,7\% em 2025 com um lucro de aproximadamente U\$ 10,55 bilhões, desta forma, esforços significativos de pesquisas estão se concentrando na busca, na produção ou síntese de ingredientes com potencial prebiótico (MANO et al., 2017).

$\mathrm{O}$ aperfeiçoamento de novas tecnologias é proveniente do êxito na relação entre as organizações como, indústria, empresas e instituições de pesquisa. Assim, o desenvolvimento de estudos relacionados a prospecção tecnológica tem crescido em ritmo cada vez mais acelerado, possibilitando verificar quais os nichos de mercado estão em ascensão, tecnologias mais relevantes, parceiros envolvidos e concorrência, através da coleta, análise e autenticação de dados sobre os avanços tecnológicos e científicos da área de interesse por meio da busca de informações a partir de documentos como as patentes, por exemplo (LEE; JEON; PARK, 2011).

Diante disso, o presente trabalho teve como objetivo realizar um levantamento do cenário nacional e internacional de patentes relacionadas aos prebióticos, analisando alguns parâmetros como quantidade de publicações e pedidos de patentes por ano, países de origem, tipo de documento, organizações requerentes, principais Classificações Internacionais de Patentes (IPC), entre outros.

\section{FUNDAMENTAÇÃO TEÓRICA}

Prebióticos

O termo prebiótico foi definido pela primeira vez como "um ingrediente alimentar não 
digerível que afeta beneficamente o hospedeiro ao estimular seletivamente o crescimento e/ou a atividade de uma ou de um número limitado de bactérias no cólon, e assim melhora a saúde do hospedeiro" (GIBSON; ROBERFROID, 1995). Porém, devido ao avanço nas pesquisas, a Associação Científica Internacional de Probióticos e Prebióticos (ISAPP) redefiniu o conceito para "um substrato que é utilizado seletivamente por microorganismos hospedeiros, conferindo um benefício à saúde" (GIBSON et al., 2017).

Para que um ingrediente seja considerado um prebiótico, alguns critérios devem ser levados em consideração, como: i) apresentar resistência à degradação por ácidos e enzimas através do sistema gastrointestinal e resistência à absorção gastrointestinal; ii) manter a fermentação sustentada pelas células probióticas do cólon e iii) estimular seletivamente o crescimento e/ou atividade das bactérias do cólon associados à saúde e ao bem-estar. A maioria desses efeitos estão associados ao funcionamento e metabolismo do cólon, as mudanças na microbiota, seus produtos metabólicos e efeitos na bioquímica do hospedeiro, no qual constituem a base do fundamento lógico da associação entre prebióticos e benefícios à saúde (ILLANES; GUERRERO, 2016).

Além da importância para manter o equilíbrio da microbiota intestinal, entretanto, apenas alguns compostos de carboidratos são considerados prebióticos e alguns deles podem ser produzidos industrialmente com o uso de enzimas como os frutooligossacarídeos (FOS), obitidos pela ação das enzimas frutosiltransferases, $\beta$-frutofuranosidase e inulinases; galacto-oligossacarídeos (GOS) e lactulose ambos obtidos pelas reações catalisadas pela enzima $\beta$-galactosidase, e inulina, os quais favorecem o crescimento de Lactobacillus spp. e/ou Bifidobacterium spp. (AZAD et al., 2020).

Existem muitos tipos de prebióticos dietéticos, a maioria deles à base de carboidratos, mas evidências recentes demonstraram que outras substâncias, como compostos fenólicos, fitoquímicos e ácidos graxos conjugados, também podem se enquadrar nessa definição (FARIAS et al., 2019). Os polifenóis são compostos bioativos presentes em várias fontes alimentares, incluindo chá verde, vinho tinto, mirtilo, semente de uva, aloé vera, agave, pêssegos, alho e quando atingem o cólon, entram em contato direto com os micróbios intestinais, resultando em uma interação complexa e multidirecional, que mostra potente atividade prebiótica. Além disso, algumas substâncias como proteínas, ácidos graxos poliinsaturadas, ácidos orgânicos e metabólitos bacterianos foram propostos como substâncias prebióticas porque podem ser usados para potencializar o efeito dos probióticos (GIBSON et 
Para os prebióticos servirem como ingredientes alimentares funcionais, eles não devem afetar negativamente as propriedades organolépticas do produto e devem ser quimicamente estáveis em tratamentos de processamento de alimentos, como calor, baixo $\mathrm{pH}$ e condições de reação de Maillard. Se houver uma alteração química e/ou degradação dos prebióticos em seus componentes mono e dissacarídeos, eles não estarão disponíveis para metabolismo bacteriano, nem fornecer estimulação seletiva de microrganismos, ou exercer seus mecanismos para melhorar a saúde (NERI-NUMA; PASTORE, 2020).

Leguminosas, frutas e legumes, como trigo, aveia, cevada, feijão marinho, feijão branco, feijão preto, lentilhas, grão-de-bico, tomates, cebola, alho, chicória, verduras, alho-poró, cebolinha, espinafre, alcachofras de Jerusalém, bananas são ricos em fibras prebióticas. Geralmente, os agentes prebióticos benéficos são classificados como polióis (álcoois de açúcar), oligossacarídeos e fibras solúveis (MOHANTY et al., 2018). Os prebióticos são empregados em diversas formulações de alimentos, como bebidas, panificação, carnes e laticínios, com o intuito de aumentar seu potencial saudável ou para melhorar suas propriedades tecnológicas. Além disso, melhoram recursos sensoriais, como frescor e fornecem uma composição nutricional mais equilibrada porque são frequentemente usados como fibra dietética e adicionados como um ingrediente de volume de baixo valor energético (HURTADO-ROMERO et al., 2020).

\section{Prospecção tecnológica}

Uma das formas de acompanhar as informações tecnológicas em nicho específico é através da prospecção tecnológica de patentes. A prospecção tecnológica é um método que visa realizar um levantamento de tecnologias existentes, determinar o estágio de maturidade da tecnologia em questão e como ela se insere na sociedade. Além disso, são identificados aspectos de tecnologias concorrentes e lacunas a serem preenchidas, onde é possível que determinada tecnologia ou suas variações sejam competitivas. As tecnologias afins também são buscadas e podem ser incorporadas à tecnologia que está sendo mapeada, formando parcerias com alto potencial de sucesso, podendo aumentar seu impacto sinérgico (QUINTELLA et al., 2011; PROCACI et al., 2016).

A prospecção tecnológica através de patentes constitui uma poderosa ferramenta de apoio à decisão, considerando a riqueza de informações contidas neste tipo de documento, 
permitindo a identificação de tecnologias relevantes, parceiros envolvidos, nichos de mercado para desempenho, inovações e movimentos da concorrência, além disso, cerca de $2 / 3$ da informação tecnológica está disponibilizada somente em documentos de patentes (DEORSOLA et al., 2011). A patente compreende uma fonte de informação mais formal, constituída por dados técnicos e jurídicos de invenção. Assim, é fundamental que os pesquisadores utilizem as informações encontradas em documentos de patentes por se constituírem como a principal fonte de conhecimento técnico existente, caso contrário, desperdiçam uma importante fonte sobre o desenvolvimento tecnológico de determinado setor (MARQUES et al., 2016).

A metodologia que envolve a prospecção tecnológica deve ser desmistificada, tornando-se ferramenta rotineira e contribuindo para facilitar a apropriação com qualidade da Propriedade Intelectual (PI) e desta forma melhorar a gestão da inovação, ao aumentar o senso crítico e ampliar a visão dos gargalos tecnológicos e das oportunidades (QUINTELLA et al., 2011).

\section{METODOLOGIA}

A pesquisa de patentes foi realizada entre os dias 16 e 23 de abril de 2021 nas seguintes bases de dados: Derwent, Espacenet, INPI, Lens, Patentscope e USPTO. A realização das buscas sobre prebióticos ocorreram nos intervalos de tempo disponíveis em cada base de dados e utilizando os procedimentos metodológicos descritos nos tópicos posteriores.

\section{Derwent}

O Derwent Innovations Index é uma ferramenta que oferece acesso a mais de 30 milhões de invenções descritas em mais de 65 milhões de documentos de patentes. Esta base de dados permite a pesquisa de patentes a todos os níveis de uma organização por meio de pesquisas simples. A cobertura inclui registros de patentes de Derwent World Patents Index e informações de citação de patentes de Derwent Patents Citation Index. No Brasil, o Derwent possui acesso livre através de universidades, institutos federais e P\&D, pelo portal da CAPES. A metodologia utilizada compreende as etapas abaixo.

- Acesse:https://www-periodicos-capes-gov-br.ez19.periodicos.capes.gov.br/

- Na página inicial: Buscar $\rightarrow$ Buscar base $\rightarrow$ Digite "Web of Science" $\rightarrow$ Clique em 
"Derwent Innovations Index - DII (Web of Science/ Clarivate Analytics)".

- Pesquisa básica: Tópico: "prebiotic” OU “prebiotics”.

- Entre em "Pesquisar".

\section{Espacenet}

O Espacenet é disponibilizado pelo Escritório Europeu de Patentes (European Patent Office, EPO), junto com a Comissão Europeia e vários escritórios nacionais e regionais de patentes. Trata-se de uma plataforma online, acessível para iniciantes e especialistas e que é atualizada diariamente. Contém dados sobre mais de 120 milhões de documentos de patentes em todo o mundo, desde 1782 até hoje. A metodologia utilizada compreende as etapas abaixo.

- Acesse: https://worldwide.espacenet.com/.

- Na página inicial: Acesso rápido $\rightarrow$ Espacenet clássico.

- Ir em "Busca avançada".

- No campo "Escolha a coleção que deseja pesquisar", selecione "No mundo todocoleção de pedidos publicados de mais de 100 países”.

- Item "Título ou resumo" preenchido com "prebiotic ou prebiotics".

- Clique em "Procurar".

INPI

O Instituto Nacional da Propriedade Industrial (INPI) é o órgão regulamentador responsável pelo aperfeiçoamento, disseminação e gestão do sistema brasileiro de concessão e garantia de direitos sobre uma invenção tecnológica, uma marca ou modelo industrial, entre outros, para a indústria. Seus serviços compreendem o registro e concessão de marcas, patentes, desenho industrial, transferência de tecnologia, indicação geográfica, programa de computador e topografia de circuitos integrados. A metodologia utilizada compreende as etapas abaixo.

- Acesse: https://www.gov.br/inpi/pt-br.

- Na página principal: clique em Patentes $\rightarrow$ Busca $\rightarrow$ Faça login.

- Acesse "Patentes". 
- Na pesquisa básica: selecione "todas as palavras" $\rightarrow$ (prebiótico ou prebióticos no título" e "prebiótico ou prebióticos no resumo").

- Entre em "Pesquisar".

Lens

O Lens é uma plataforma que foi lançada nos anos 2000 como uma iniciativa da Cambia, organização não governamental sediada em Camberra, Austrália, em parceria com a Queensland University of Technology. Os dados de patentes são oriundos do Escritório Europeu de Patentes, do Escritório Americano de Patentes, do Escritório Australiano de Patentes e dos documentos relacionados ao Tratado de Cooperação em termos de Patentes da WIPO, com informações bibliográficas a partir de 1907. Esse banco de dados possui mais de 127 milhões de registros de patentes de 105 jurisdições e 70,1 de famílias de patentes até o começo do primeiro semestre de 2021. A metodologia utilizada compreende as etapas abaixo.

- Acesse: https://www.lens.org/.

- Na página inicial: Patentes $\rightarrow$ Pesquisa estruturada de patentes.

- Campo de pesquisa: Título (prebiotic ou prebiotics) OU Resumo (prebiotic ou prebiotics).

- Entre em "Pesquisar".

Patentscope

O Patentscope é a base de dados da Organização Mundial da Propriedade Intelectual (OMPI ou WIPO em inglês). Ela proporciona acesso de forma gratuita a documentos de vários países, incluindo os depósitos via PCT (Tratado de Cooperação em matéria de Patentes). Permite fazer pesquisas em 93 milhões de documentos de patentes, além de 4,0 milhões de pedidos de patentes internacionais (PCT) que são publicados desde 1978. A metodologia utilizada compreende as etapas abaixo.

- Acesse: https://www.wipo.int/portal/en//.

- Na página inicial: Recursos $\rightarrow$ Base de dados IP (PATENTSCOPE) $\rightarrow$ Clique em "Acesse a base de dados PATENTSCOPE".

- Pesquisa simples: Campo "página de cobertura" $\rightarrow$ Termo pesquisado 


\section{응

"FP:((EN_TI:("prebiotic" ou "prebiotics") OU EN_AB:("prebiotic" ou "prebiotics")))".

- Clique em $\mathrm{Q}$.

\section{USPTO}

O United States Patent and Trademark Office é o escritório americano que concede patentes para a proteção de invenções e registra marcas. Possui uma das mais completas bases, com busca altamente refinada. As patentes referentes aos anos de 1790 a 1975 apresentam informações restritas e a partir de 1976 está disponível o texto completo das patentes. A metodologia utilizada compreende as etapas abaixo.

- Acesse: https://www.uspto.gov/.

- Na página inicial: Encontre rápido $\rightarrow$ Patentes $\rightarrow$ Clique em "PatFT".

- Campo de pesquisa preenchido com: Termo 1 (prebiotic OU prebiotics) no campo 1 (Título) OU Termo 2 (prebiotic OU prebiotics) no campo 2 (Resumo).

- Selecione anos: “1976 para exibir [texto completo]”.

- Entre em "Pesquisar".

Análise de dados

A partir das bases de dados selecionadas, a primeira etapa do estudo consistiu em identificar qual plataforma apresenta um banco de dados mais abrangente quanto ao número de invenções de patentes. Em seguida as patentes selecionadas da base de dados mais completa determinada na etapa anterior, tiveram a análise dos seguintes dados: Frequência de publicação de documentos e pedidos de patentes ao longo dos anos, status de depósito, país de prioridade, organizações requerentes e Classificação Internacional de Patentes (IPC). Os resultados foram apresentados na forma de gráficos, permitindo conhecer a distribuição temporal dos depósitos, o número de registros relacionados a utilização de celulases, a distribuição dos depósitos a nível mundial, quais instituições de pesquisa, indivíduos e empresas privadas que são detentoras tecnologia e a quantidade de documentos dispostos, entre outras informações. Para a análise das patentes depositadas no Brasil, utilizou-se a metodologia descrita anteriormente do INPI. 


\section{RESULTADOS E DISCUSSÃO}

Após a realização da pesquisa nas bases de dados, foi possível determinar a quantidade de patentes sobre prebióticos em cada plataforma (Tabela 01). A partir dessa busca, observou-se que o banco de dados Lens apresentou o maior número de documentos de patentes (5241) em comparação com as outras bases. Desta forma, o Lens foi selecionado para a realização do monitoramento tecnológico sobre os prebióticos.

Tabela 01: Número de registros de patentes em cada banco de dados.

$\begin{array}{cc}\text { Base de dados } & \text { Quantidade de patentes } \\ \text { Lens } & 5241 \\ \text { Derwent } & 4479 \\ \text { Espacenet } & 4289 \\ \text { Patentscope } & 4228 \\ \text { USPTO } & 226 \\ \text { INPI } & 122\end{array}$

Fonte: O Autor, por pesquisa direta nos bancos de dados Lens, DERWENT, Patentscope, Espacenet, USPTO e INPI (2021).

A Figura 01, apresenta o comportamento quantitativo de patentes no período de 1996 a 2020. Observou-se um aumento gradativo, com pequenas oscilações de crescimento e decréscimo até o ano de 2013. Em 2014, no entanto, houve um aumento significativo da quantidade de patentes em comparação aos anos anteriores, com recorde no número de depósitos de patentes, totalizando 537 registros. Com base nos resultados para a análise das patentes quanto ao tipo de documento, $75 \%$ correspondem a pedido de patente, $15 \%$ referem-se a patentes que atenderam aos critérios e foram concedidas e os $10 \%$ restantes compreendem a documentos identificados desconhecidos, ambíguos, relatórios de pesquisa, patente limitada e alterada (Figura 02).

Figura 01: Distribuição de publicação e pedidos de patentes ao longo dos anos. 


\section{B.

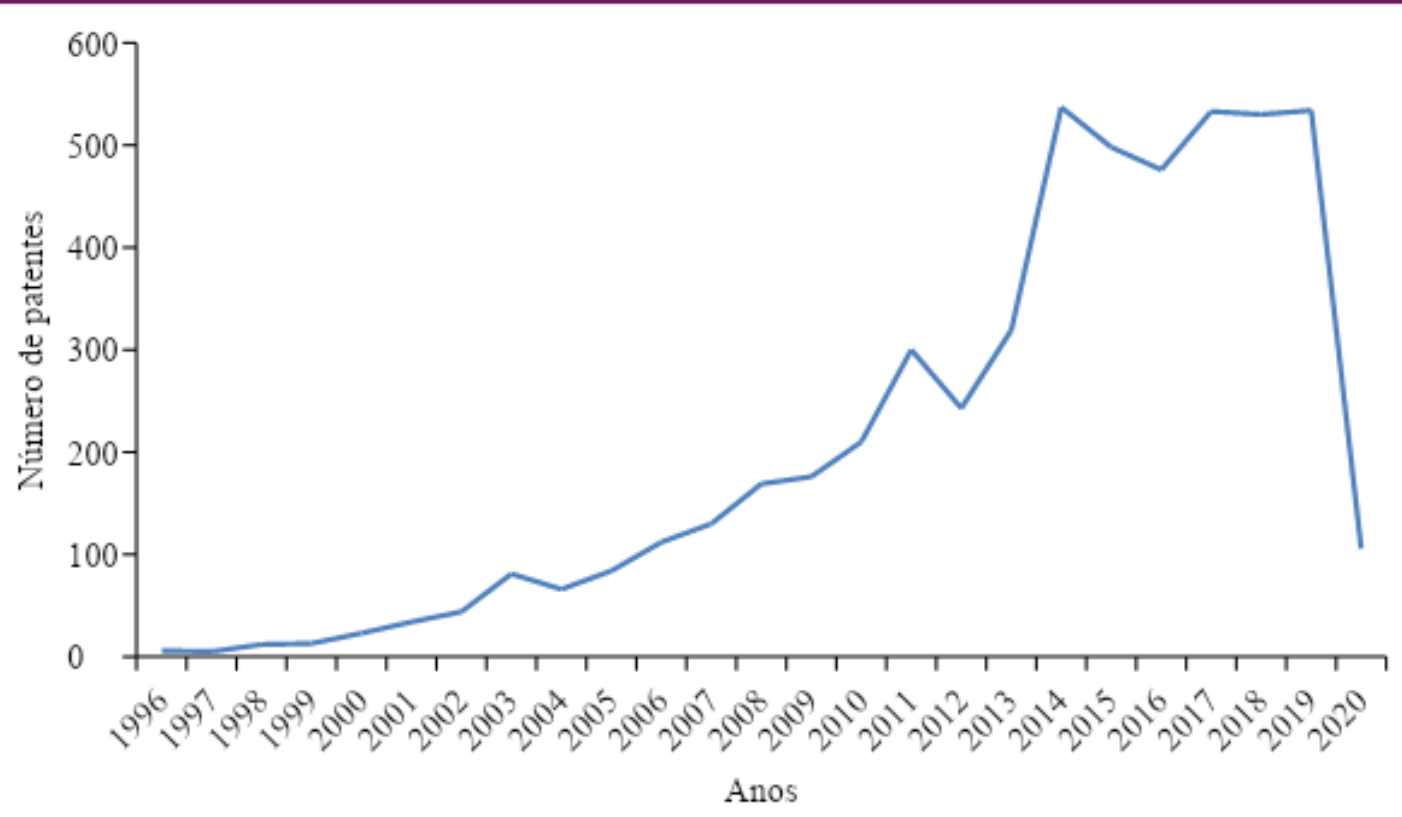

PICDED

Fonte: O Autor, por pesquisa direta no banco de dados de patentes Lens (2021).

Figura 02: Tipo de documento das patentes.



= Pedido de patente

- Patente concedida

autros

Fonte: O Autor, por pesquisa direta no banco de dados de patentes Lens (2021).

Dentre as 10 principais jurisdições, a China lidera como a principal jurisdição depositante de patentes sobre prebióticos com 1980 registros, equivalendo a aproximadamente $38 \%$ do total de registros (Figura 03). De acordo com o relatório de Indicadores Mundiais de Propriedade Intelectual 2020, a China se destacou como a principal fonte de pedidos internacionais de patentes, seguido dos Estados Unidos e Japão (WIPO, 
2020).

Figura 03: Principais jurisdições depositantes de patentes.



- China

- Estados Unidos

= Wo-Wipo

- Patentes européias

- Canadá

" Austrália

- Rússia

- México

- República da Coréia

- Japão

Fonte: O Autor, por pesquisa direta no banco de dados de patentes Lens (2021).

Com relação as principais organizações requerentes de documentos de patentes, verificou-se que a Nestec $S A$ foi a organização que mais realizou depósitos de patentes (175 registros) e é responsável por oferecer pesquisa comercial e serviços de consultoria para a Nestlé S.A. e suas subsidiárias, os resultados das 10 principais organizações pode ser observado na Figura 04. A empresa também presta serviços de pesquisa científica e desenvolvimento tecnológico além disso, opera como subsidiária do The Nestlé Group, que é a empresa líder mundial em nutrição, saúde e bem-estar.

Figura 04: Principais organizações requerentes de patentes (Critério Top 10). 




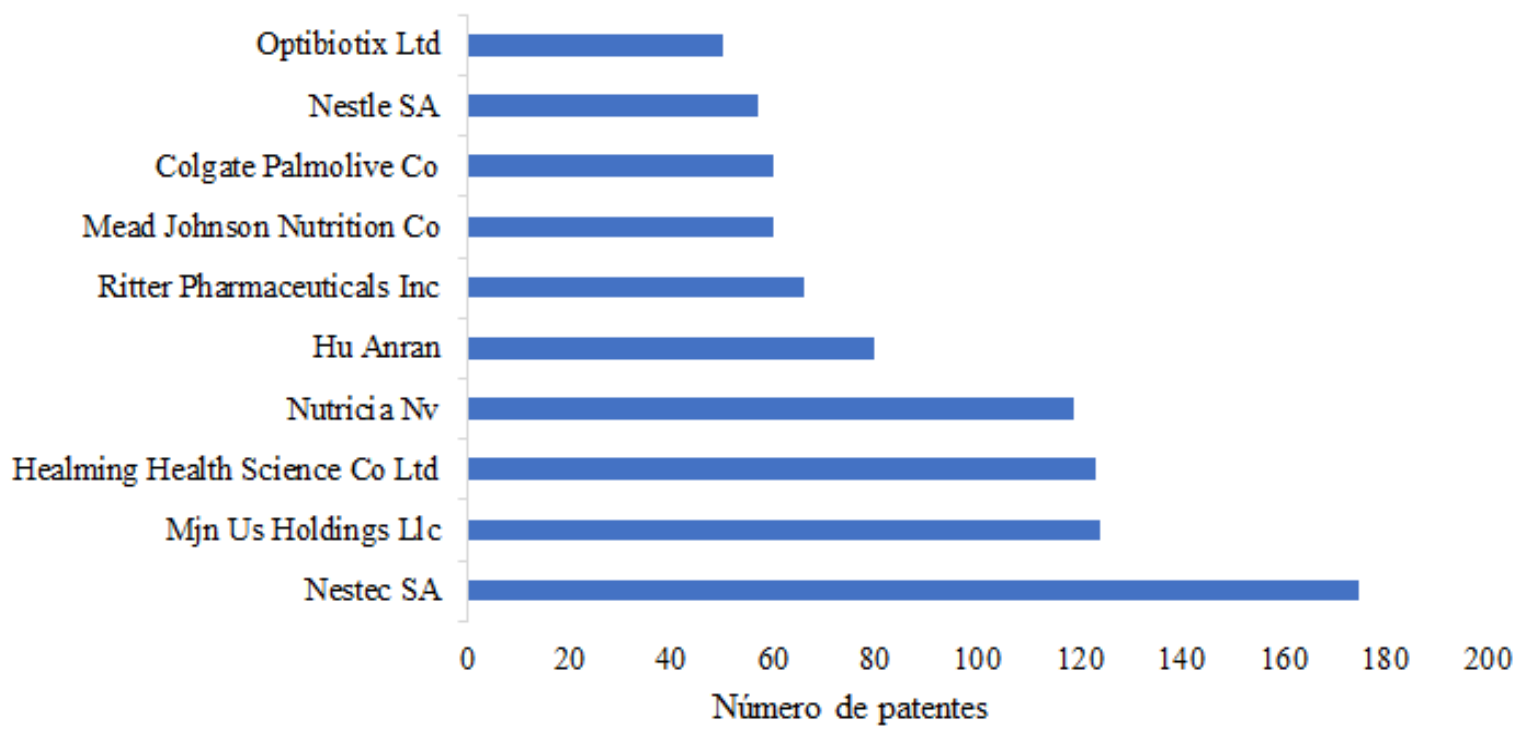

Fonte: O Autor, por pesquisa direta no banco de dados de patentes Lens (2021).

Dentre as patentes de titularidade da Nestec $S A$, pode-se citar:

i) No da patente MX 2011012955 A (publicada em 2012): refere-se a uma composição nutricional prebiótica, em particular dirigida a bebês e/ou crianças desmamadas que melhora o desempenho cognitivo, em particular a aprendizagem e a memória da criança.

ii) $\mathrm{N}^{\mathrm{o}}$ da patente US 2017/0273997 A1 (publicada em 2017): propõe uma composição nutricional composta por oligossacarídeos selecionados que reduz a abundância de bactérias estreptococos no intestino de bebês ou mamíferos jovens. A redução do estreptococo e do equilíbrio da microbiota relacionada afeta e reduz o risco de adiposidade ou obesidade futuramente.

O eixo microbiota-intestino-cérebro se refere à extensa rede de comunicação entre a microbiota que reside no intestino, o intestino e o cérebro. A microbiota e o cérebro se comunicam por diferentes vias, como a inervação vagal, metabólitos microbianos e neurotransmissores derivados de micróbios (Ácido gama-aminobutírico (GABA), serotonina, catecolaminas e acetilcolina). A microbiota é necessária para a estrutura, desenvolvimento e função do cérebro, pois já foi demonstrado que o sistema serotonérgico não se desenvolve adequadamente sem micróbios e a atividade do hipocampo também foi associada à presença de micróbios (ROMO-ARAIZA; IBARRA; 2020).

De acordo com Kallus e Brandt (2012), o mecanismo que relaciona a microbiota intestinal e a obesidade não é bem compreendido, mas o que está bem estabelecido é que a 


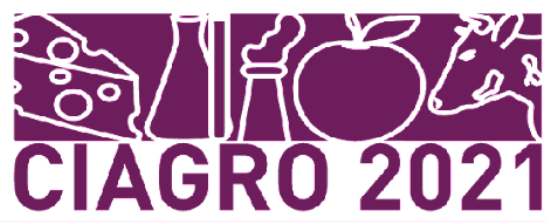

microbiota intestinal pode aumentar a energia da dieta e regular a composição de ácidos graxos. Alguns ensaios clínicos demonstraram que a ingestão de prebióticos foi associado a PIuma melhora significativa na saciedade, glicose pós-prandial e concentrações de insulina em indivíduos adultos. O consumo de uma mistura de inulina/oligofrutose também demonstrou aumentar Bifidobacterium spp. e Fae calibacterium prausnitzii, que se correlacionaram negativamente com lipopolissacarídeos e Bifidobacterium spp. que se correlacionam negativamente com porcentagem de massa gorda e colesterol LDL. Esses resultados promissores em adultos justificam a avaliação de prebióticos como uma intervenção dietética para modular a microbiota intestinal e os resultados metabólicos na obesidade pediátrica (NICOLUCCI et al., 2017).

Os documentos de patentes também foram analisados em relação a Classificação Internacional de Patentes (IPC) que serve para classificar o conteúdo técnico de um documento de patente (ou outra invenção) (Tabela 02). Foram identificadas 90 classificações diferentes, no qual 30\% se referem a seção A23L que compreendem alimentos, produtos alimentícios ou bebidas não alcoólicas, não abrangidos pelas subclasses A21D ou A23B-A23J; sua preparação ou tratamento, por exemplo, cozinha, modificação de qualidades nutritivas, tratamento físico (modelagem ou trabalho, não totalmente abrangidos por esta subclasse, A23P); preservação de alimentos ou alimentos, em geral. Vale ressaltar que um mesmo documento pode abranger diferentes IPC's.

Tabela 02: Principais subclasses dos IPC's nos registros de patentes sobre prebióticos.

IPC

\section{Descrição}

Modificação das qualidades

A23L33/00 nutritivas dos alimentos, produtos dietéticos, preparação ou tratamento dos mesmos.

A23L1/30 Não encontrado

Carboidratos, Açúcares derivados do mesmo sorbitol;

Oligossacarídeos, ou seja, com três a cinco radicais sacáridos ligados um ao outro por ligações glicosídicas.

A23L33/135 Bactérias ou seus derivados, ex. Probióticos.

A61K35/747 Lactobacilos, ex. L. acidophilus ou

\section{Contagem de} registros

1178 22,48

681

662

558

10,64

519 


\begin{tabular}{|c|c|c|c|}
\hline A61P1/00 & $\begin{array}{l}\text { L. brevis } \\
\text { Medicamentos para distúrbios do } \\
\text { trato alimentar ou do sistema } \\
\text { digestivo }\end{array}$ & 479 & 9,14 \\
\hline A61K35/74 & $\begin{array}{l}\text { Bactérias (uso terapêutico de uma } \\
\text { proteína bacteriana). }\end{array}$ & 475 & 9,06 \\
\hline A23L33/21 & $\begin{array}{l}\text { Adição de substâncias } \\
\text { substancialmente indigeríveis, ex. } \\
\text { fibras dietéticas (adição de agentes } \\
\text { gelificantes ou espessantes). }\end{array}$ & 404 & 7,71 \\
\hline A23L33/125 & $\begin{array}{l}\text { Uso de aditivos sem precedência; } \\
\text { contendo xaropes de carboidratos } \\
\text { contendo açúcares } \\
\text { álcoois de açúcar } \\
\text { hidrolisados de amido substâncias } \\
\text { indigestas. }\end{array}$ & 391 & 7,46 \\
\hline A61K31/715 & $\begin{array}{l}\text { Polissacarídeos, isto é, tendo mais } \\
\text { de cinco radicais sacarídeos ligados } \\
\text { uns aos outros por ligações } \\
\text { glicosídicas; seus derivados, e. } \\
\text { éteres, ésteres. }\end{array}$ & 388 & 7,40 \\
\hline
\end{tabular}

O desenvolvimento desse setor no mercado está relacionado a diversos fatores, inclusive o interesse dos consumidores por alimentos que proporcionem benefícios à saúde. A utilização de prebióticos como componentes alimentares apresenta múltiplas vantagens, uma vez que melhoram as características sensoriais e fornecem uma composição nutricional mais bem balanceada. Quando os prebióticos são empregados em produtos de panificação e cereais matinais, isso representa um grande progresso em comparação com a fibra dietética clássica. Prebióticos fornecem mais frescor em salgadinhos e cereais e prolongam a prateleira vida. Eles também mantêm pães e bolos úmidos e frescos por um muito tempo. Sua solubilidade permite a incorporação da fibra em sistemas líquidos como bebidas, laticínios e produtos para barrar. Os prébióticos também são frequentemente utilizados como fibra alimentar em comprimidos e em alimentos funcionais, particularmente em gamas inteiras de produtos lácteos e pães, pois os ingredientes prebióticos aumentam a viabilidade de bactérias intestinais saudáveis (AL-SHERAJIA et al., 2013).

Partindo das combinações de palavras-chaves descritas sobre a plataforma brasileira, também foi possível realizar uma triagem de diversos indicadores relacionados aos registros de patentes depositados na autarquia federal brasileira INPI. A busca nessa base de dados 


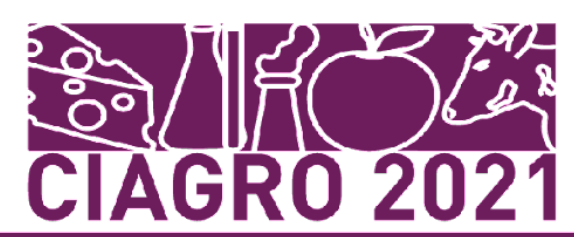

recuperou 122 pedidos de patentes, a distribuição das patentes de acordo com o ano de publicação (Figura 5), sendo 2017 seu ápice com 13 depósitos. No entanto, é importante


ressaltar que o processo de publicação do relatório de inovação só será concluído caso o documento atenda a todas exigências do sistema de patente e no Brasil, tal procedimento pode durar até um ano e meio após realização do pedido de patente.

Figura 05: Distribuição de publicação e pedidos de patentes ao longo dos anos no Brasil.

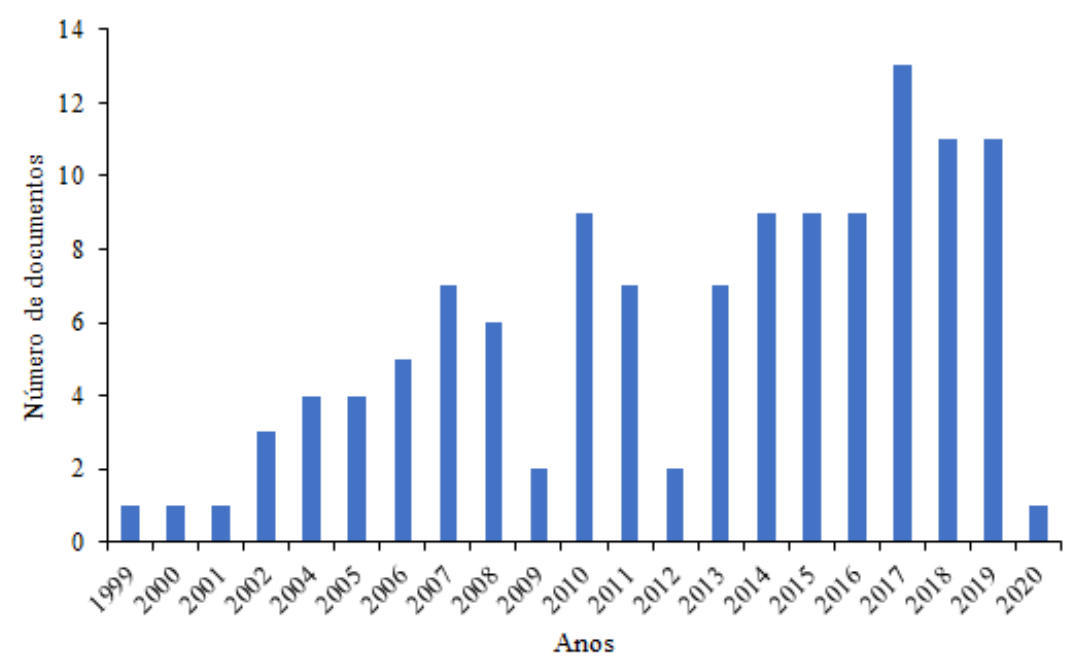

Fonte: O Autor, por pesquisa direta no banco de dados de patentes INPI (2021).

Com relação aos países de origem dos pedidos de patentes residentes no Brasil (Figura 06), o Brasil é o principal depositante com 59 documentos, equivalente a $48 \%$ do total de registros, em seguida tem o Estados Unidos com 19\% e os 33\% restante são provenientes de outros países como Suíça, Alemanha, Dinamarca, Holanda, Itália, Rússia, França, México, Bélgica, Índia, China, Espanha, Panamá, Singapura e Suécia.

Figura 06: Países dos pedidos de patentes no INPI. 


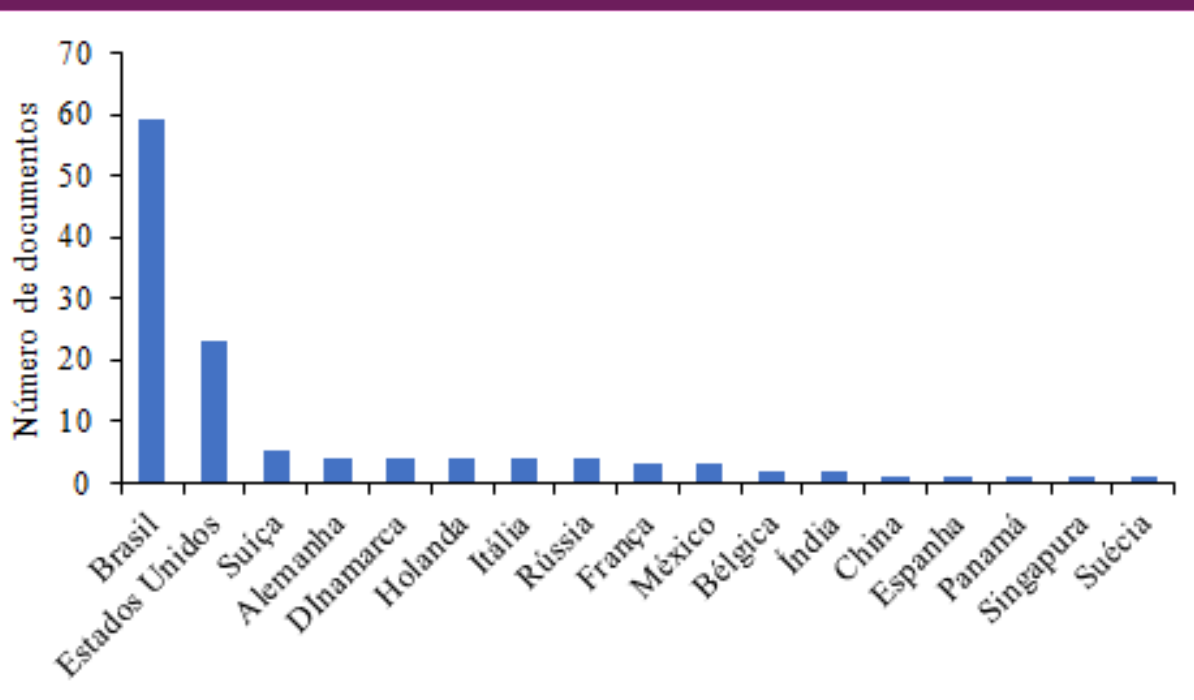

Paises

Fonte: O Autor, por pesquisa direta no banco de dados de patentes INPI (2021).

Em relação ao status do documento, a patente pode ser classificadas como depositada ou concedida. Neste estudo, $88 \%$ compreendem as patentes depositadas e apenas $12 \%$ do total correspondem a patentes concedidas. De acordo com informações dispostas no guia básico do endereço eletrônico do Instituto Nacional da Propriedade Industrial (INPI), as patentes no Brasil podem ser de dois tipos: Patente de invenção (PI) para produtos ou processos que apresentem uma nova tecnologia e Patente de Modelo de Utilidade (MU) quando confere apenas melhorias e aperfeiçoamento no uso ou na fabricação de metodologias e objetos já existentes. Neste monitoramento tecnológico, $66 \%$ dos documentos correspondem patentes do tipo MU e as demais são do tipo PI. Dentre as patentes concedidas, apenas $19 \%$ são classificadas como patente de invenção (PI) (Figura 07).

Figura 07: Distribuição do tipo de documento e situação dos pedidos de patentes no INPI. Onde: MU - Modelo de utilidade; PI - Patente de Invenção. 


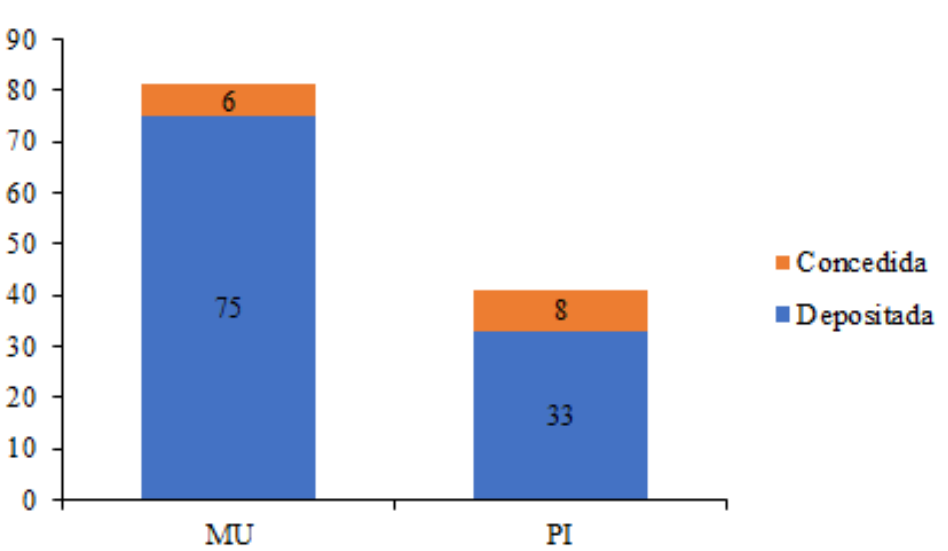

Fonte: O Autor, por pesquisa direta no banco de dados de patentes INPI (2021)

Com base no boletim mensal de propriedade industrial disponibilizado no INPI, até o mês de outubro de 2020, 78 países solicitaram proteção de patentes, entre os países que mais depositaram pedidos de patentes de invenção, sendo os principais os Estados Unidos (30\%), Brasil (21\%), Alemanha (7\%), Japão (7\%) e China (5\%). Entre os depósitos de modelo de utilidade, depositantes residentes do Brasil foram responsáveis por 99\% dos pedidos (INPI, 2020).

Com relação ao depositante, verificou-se que assim como foi apresentado na seção anterior no estudo de patentes a nível global, a maior parte das patentes também são de empresas privadas com $54 \%$ pedidos de patentes, em seguida por $37 \%$ pedidos de patentes de instituições públicas sendo elas universidades e institutos federais, e 9\% por pessoas físicas, conforme apresentado na Figura 8.

Figura 08: Distribuição por depositante dos documentos nos pedidos patentes envolvendo prebióticos no Brasil.

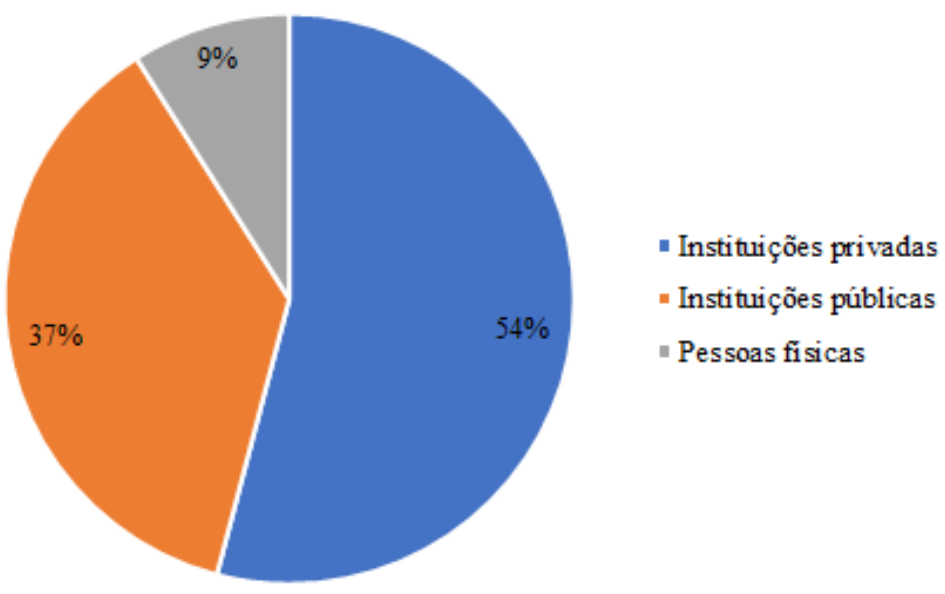

Fonte: O Autor, por pesquisa direta no banco de dados de patentes INPI (2021). 
Em relação ao período janeiro-outubro de 2020, entre os depósitos de residentes, a categoria de pessoas físicas foi responsável por $42 \%$ do total de patentes de invenção, seguido das instituições de pesquisa e ensino e governo (27\%) e empresas de médio e grande porte (18\%). Analisando as patentes classificadas como modelo de utilidade, a categoria de pessoas físicas também se destacou como a principal depositante de patentes (60\%), seguido das MEI, ME e EPP (22\%) (INPI, 2020).

Segundo um ranking liberado pelo Instituto Nacional de Propriedade Intelectual (INPI) em setembro de 2020, a Universidade Federal da Paraíba se destacou, pelo segundo ano consecutivo, como a instituição mais depositante no ano de 2019, com 100 pedidos de patentes enquanto que a Universidade de São Paulo (USP) ocupa a $8^{\text {a }}$ colocação, com 45 registros (INPI, 2019), demonstrando o potencial do ensino público superior para contribuição científica tanto à indústria como para a sociedade.

Contudo, os esforços existentes para gerar inovações tecnológicas no Brasil são bastante baixos. Segundo o Relatório patrocinado pelo Banco Interamericano de Desenvolvimento (BID) de avaliação das políticas recentes de incentivos à pesquisa, desenvolvimento e inovação no Brasil, afirmam que para superar esse atraso relativo é necessária uma alteração pronunciada nos gastos privados em PD\&I (Pesquisa, Desenvolvimento e Inovação) a exemplo dos países desenvolvidos. Mas é fundamental reconhecer que também são necessárias políticas sociais e educacionais adequadas para enfrentar dificuldades de "eficiência" internos e atingir um estágio caracterizado por um sistema nacional de inovação de qualidade (LIMA; RAMALHO, 2016).

\section{CONCLUSÕES}

Após a busca nas bases de dados, constatou-se que o Lens apresentou um escopo mais amplo de patentes sobre prebióticos. Analisando os resultados dessa plataforma, houve um aumento significativo de registros de patentes ao longo dos anos, sendo em 2014 o ano que apresentou número recorde de depósitos. Entre as jurisdições, a China foi o país que mais realizou depósitos de patentes (38\%). Quanto ao tipo de documento, apenas $15 \%$ dos documentos foram concedidos e a Nestec $S A$ foi a principal organização requerente de patentes sobre prebióticos.

Com relação ao INPI, o Brasil se destacou como o principal país depositante e entre as instituições, as empresas privadas são responsáveis pela maior parte dos registros de patentes. 
Porém ainda se faz necessário maiores investimentos para promoção da ciência, tecnologia e inovação. A partir dos resultados obtidos, é possível constatar que o cenário global de patentes relacionadas a prebióticos é promissor e esse estudo pode contribuir para organizações na tomada de decisões e definição de estratégias afim de estabelecer uma posição competitiva no mercado.

\section{REFERÊNCIAS}

AL-SHERAJIA, S.H.; ISMAILA, A.; MANAP, M. Y.; MUSTAFAC, S.; YUSOFA, R. M.; HASSANA, F. A. Prebiotics as functional foods: A review. Journal of fuctional foods, v. 5, n.4, p.1542-1553, 2013.

BRASIL. Ministério da Saúde. Agência Nacional de Vigilância Sanitária. Resolução n. 19, de 30 de abril de 1999. Aprova o Regulamento Técnico de Procedimentos para Registro de Alimento com Alegação de Propriedades Funcionais e ou de Saúde em sua Rotulagem. Brasília, 1999.

Acesso

em: https://www.gov.br/agricultura/pt-br/assuntos/inspecao/produtos-vegetal/legislacao-1/bibliote ca-de-normas-vinhos-e-bebidas/resolucao-no-19-de-30-de-abril-de-1999.pdf/view. Acesso em: 22 de mai. 2021.

AZAD, M. A. K.; GAO, J.; MA, J.; LI, T.; TAN, B.; HUANG, X.; YIN, J. Opportunities of prebiotics for the intestinal health of monogastric animals. Animal Nutrition, v. 6, p. 379-388, 2020.

DEORSOLA, A. C.; MOTHE, C. G.; OLIVIEIRA, L. G.; DEORSOLA, A. B. Technological monitoring of cyclodextrin e World panorama. World Patent Information, v. 39, p 41-49, 2014.

FARIAS, D. P.; ARAÚJO, F. F.; NERI-NUMA, I. A.; PASTORE, G. M. Prebiotics: Trends in food, health and technological applications. Trends in Food Science \& Technology, v. 93, p. 23-35, 2019.

GIBSON, G. R.; ROBERFROID, M. B. Dietary modulation of the human colonie microbiota: Introducing the concept of prebiotics. The Journal of nutrition, v. 125, ed. 6, p. 1401-1412, 1995.

GIBSON, G. R.; HUTKINS, R.; SANDERS, M. E.; PRESCOTT, S. L.; REIMER, R. A.; SALMINEN, S. J.; SCOTT, K.; STANTON, C.; SWANSON, K. S., CANI, P. D., VERBEKE, K.; REID, G. Expert consensus document: The International Scientific Association for Probiotics and Prebiotics (ISAPP) consensus statement on the definition and scope of prebiotics. Nature Reviews Gastroenterology \& Hepatology, 2017.

HURTADO-ROMERO, A.; TORO-BARBOSA, M. D.; GARCIA-AMEZQUITA, L. E.; GARCÍA-CAYUELA, T. Innovative technologies for the production of food ingredients with prebiotic potential: Modifications, applications, and validation methods. Trends in Food Science \& Technology, v. 104, p. 117-131, 2020.

ILLANES, A.; GUERRERO, C. Functional Foods and Feeds. Lactose-Derived Prebiotics, 
cap. 2, p. 35-86, 2016.

INPI- Instituto Nacional da Propriedade Industrial. RANKINGS DOS DEPOSITANTES RESIDENTES EM 2019. Disponível em: https://cct.ufcg.edu.br/wp-content/uploads/2020/09/Ranking-dos-Depositantes-Residentes-em -2019-INPI.pdf. Acesso em: 27 de abr. 2021.

INPI- Instituto Nacional da Propriedade Industrial. Indicadores de Propriedade Industrial. Boletim mensal de Propriedade Industrial, Rio de Janeiro, v.5, n.11 p. 1-20, nov. 2020.

KALLUS, S.J.; BRANDT, L. J. The intestinal microbiota and obesity. Journal of Clinic Gastroenterology, v. 46, n. 1, 2012.

LEE, C.; JEON, J.; PARK, Y. Monitoring trends of technological changes based on the dynamic patent lattice: A modified formal concept analysis approach. Technological Forecasting and Social Change, v. 78, ed. 4, p. 690-702, 2011.

LIMA, M. G.; RAMALHO, W. Avaliação de patentes: Modelos e estudo de um caso de propriedade de uma IFES. In: IV Simpósio Internacional de Gestão de Projetos, Inovação e Sustentabilidade, 2016. Anais do V SINGEP. São Paulo, 2016.

MANO, M. C. R.; NERI-NUMA, I. A.; SILVA, J. B. DA, PAULINO, B. N.; PESSOA, M. G.; PASTORE, G. M. Oligosaccharide biotechnology: An approach of prebiotic revolution on the industry. Applied Microbiology and Biotechnology, v. 102, n. 1, p. 17-37, 2017.

MARQUES, H. R.; PEREIRA, R. M.; GARCIA, M. O.; GAVA, R. Monitoramento tecnológico: um estudo de uma patente da Universidade Federal de Viçosa. Revista Gestão \& Tecnologia, Pedro Leopoldo, v. 16, n. 3, p. 110-137, 2016.

MOHANTYA, D.; MISRAB, S.; MOHAPATRAC, S.; SAHUD, P. S. Prebiotics and synbiotics: Recent concepts in nutrition. Food Bioscience, v. 28, p. 152-160, 2018.

NERI-NUMA, I. A., PASTORE, G. M. Novel insights into prebiotic properties on human health: A review. Food Research International, v. 131, 2020.

NICOLUCCI, A. C.; HUME, M. P.; MARTÍNEZ, I.; MAYENGBAM, S.; WALTER, J.; REIMER, R. A. Prebiotics Reduce Body Fat and Alter Intestinal Microbiota in Children Who Are Overweight or With Obesity. Gastroenterology, v. 153, n. 3, p. 711-722, 2017.

NITHYABALASUNDARI, S.; NIVEDITA, V.; CHAKRAVARTHY, M.; SRISOWMEYA, G.; USHA ANTONY; NANDHINI DEV, G. Characterization of microbial polysaccharides and prebiotic enrichment of wheat bread with pullulan. LWT - Food Science and Technology, v. $112,2020$.

PAVANELLI, M. A.; OLIVEIRA, E. F. T. Registro de patentes das universidades brasileiras em bases internacionais; In: XVII Encontro Nacional de Pesquisa em Ciência da Informação (XVII ENANCIB), Bahia, 2016.

PROCACI, T. B.; ARAUJO, R.; SIQUEIRA, S.; NUNES, B. P. Prospecção Tecnológica: Levantamento de Patentes, Atuação da Academia e Potenciais Inovações em Ambientes de Aprendizagem no Brasil de 2000 a 2015. Revista Brasileira de Sistemas de Informação, 


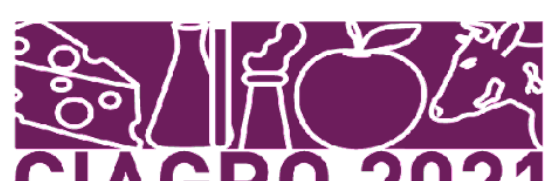

Rio de Janeiro, vol. 9, No. 3, pp. 69-88, 2016.

QUINTELLA, C. M.; MEIRA, M.; GUIMARÃES, A. K.; TANAJURA, A. S.; DA SILVA, H. R. G. Prospecção Tecnológica como uma Ferramenta Aplicada em Ciência e Tecnologia para se Chegar à Inovação. Revista Virtual de Química, v. 3, n. 5, 2011.

ROMO-ARAIZA, A.; IBARRA, A.; Prebiotics and probiotics as potential therapy for cognitive impairment. Medical Hypotheses, v. 134, 2020.

ROSA, M. C.; CARMO, M. R. S.; BALTHAZAR, C. F., GUIMARAES, J. T.; ESMERINO, E. A.; FREITAS, M. Q.; SILVA, M. C.; PIMENTEL, T. C.; CRUZ, A. G. Dairy products with prebiotics: An overview of the health benefits, technological and sensory properties. International Dairy Journal, v. 117, 2021.

\section{WIPO - World Intellectual Property Organization. Indicadores Mundiais de Propriedade Intelectual 2020. Disponível em: https://www.wipo.int/edocs/pubdocs/en/wipo_pub_941_2020.pdf. Acesso em: 24 de abr. 2021.}

